\title{
Minimal Residual Disease Detection in Pediatric Acute Lymphoblastic Leukemia
}

\author{
Miyoung $\mathrm{Kim}^{1}$ and Chan-Jeoung Park ${ }^{2}$
}

${ }^{1}$ Department of Laboratory Medicine, Hallym University Sacred Heart Hospital, Hallym University Medical Center, Hallym University College of Medicine, Anyang, '2Department of Laboratory Medicine, University of Ulsan College of Medicine and Asan Medical Center, Seoul, Korea

Minimal residual disease (MRD) status is the strongest independent prognostic factor for patients with pediatric acute lymphoblastic leukemia (ALL). Monitoring of the MRD status allows risk-adapted therapy as its absence or presence guides patient therapy and can result in significant treatment reduction or intensification, respectively. MRD assays should be sensitive (exceeding a threshold of $10^{-4}$ per current guidelines), specific, widely applicable, rapid, and technically feasible. Classical MRD assays that are widely used in pediatric ALL include multiparameter flow cytometry (MFC), which identifies aberrant immunophenotypes, and real-time quantitative polymerase chain reaction (RQ-PCR), which detects fusion transcripts or clonal immunoglobulin/T-cell receptor $(I G / T C R)$ gene rearrangements. These assays have sensitivities of $10^{-3}$ to $10^{-5}$ and have been standardized internationally. However, each assay has its own pitfalls such as false negatives caused by immunophenotypic shifts in MFC, relatively limited applicability of the fusion transcript PCR, and the technical complexity associated with designing PCR for quantifying clonal IG/TCR gene rearrangements using allele-specific oligonucleotides. Next-generation flow cytometry, next-generation sequencing, and droplet digital PCR are expected to replace classical MRD assays, given their higher sensitivities $\left(10^{-5}\right.$ to $\left.10^{-6}\right)$ and accuracies as well as greater technical feasibilities. Before their incorporation into the standard practice for care for children with ALL, these assays require further exploration to ascertain whether their higher sensitivities are clinically relevant. Furthermore, standardization and quality assurance programs should be devised to enhance the clinical adoption of these new assays. Lastly, new targets should be identified to improve the monitoring of MRD; moreover, both the methodology and clinical significance of MRD evaluation should be revisited in the era of immunotherapy.

Key Words: Leukemia, Acute lymphoblastic, Pediatric, Minimal residual disease
pISSN 2233-5250 / elSSN 2233-4580 https://doi.org/10.15264/cpho.2020.27.2.87 Clin Pediatr Hematol Oncol 2020;27:87 100

Received on August 28, 2020

Revised on October 2, 2020

Accepted on October 8, 2020
Corresponding Author: Chan-Jeoung Park
Department of Laboratory
Medicine, University of Ulsan
College of Medicine and Asan
Medical Center, 88 Olympic-ro
43-gil, Songpa-gu, Seoul 05505,
Korea
Tel: +82-2-3010-4508
Fax: +82-2-478-0884
E-mail: cjpark@amc.seoul.kr
ORCID ID: orcid.org/0000-0003-4396-8348

\section{Introduction}

Acute lymphoblastic leukemia (ALL) is a neoplasm of lymphoid progenitor cells committed to the B- $(80-85 \%$ of diagnoses), T- (20-25\%), and natural killer cell lineages (1\%) [1]. As it represents one-quarter of diagnosed childhood cancers, it is the most common malignancy in mi- nors [2,3]. Risk-adapted therapy and dose intensification strategies have greatly improved the outcomes of children with ALL, with an overall complete remission (CR) rate of $>95 \%$ for B-ALL and 70\% for T-ALL [4,5]. However, relapses still occur in $20 \%$ of children with this disease, implying the existence and proliferation of residual ALL cells that are not eradicated during therapy but remain undetected during conventional cytomorphologic 
assessment in which CR is defined as $<5 \%$ visible leukemic blasts in the bone marrow and blood [4,6-8].

Minimal residual disease (MRD) is a consequence of the abovementioned undetected cells that are responsible for relapse [4,6-8]. It can only be detected and quantified using techniques with higher sensitivity and specificity for leukemic cells and is therefore also referred to as "measurable residual disease" [9-12]. The measurement of MRD is a response-based assessment that cannot be predicted via conventional pretreatment covariates such as age, white blood cell count, and cytogenetics, indicating that responses to therapy are patient-specific and reflect the in vivo chemosensitivity of leukemic cells, drug metabolism, and other host responses [9,13]. Indeed, it has been consistently demonstrated that the prognostic value of MRD exceeds that of other pretreatment risk factors in pediatric ALL [7]. MRD status also predicts the risk of relapse and helps guide risk-adapted strategies for pediatric patients with ALL [4-8,14-19]. Current guidelines recommend the measurement of MRD using assays with sensitivities that exceed a threshold of $10^{-4}$ [20]; newer assays claim even higher sensitivities [12,21-25]. MRD assays should also be reproducible and specific enough to distinguish leukemic cells from morphologically similar non-malignant counterparts such as regenerating hematogones, which are benign lymphoid precursors comprising up to $10 \%$ of lymphoid cells in the bone marrow of patients recovering from chemotherapy or transplantation [26-29].

Classical MRD assays widely used for pediatric ALL include multiparameter flow cytometry (MFC) and real-time quantitative polymerase chain reaction (RQ-PCR) [9-11,30,31]. Newer MRD assaying technologies such as next-generation flow cytometry (NGF), next-generation sequencing (NGS), and droplet digital PCR (ddPCR) have also been developed [9-11,24,30-33]. Frequently used targets for MRD detection in pediatric ALL include aberrant immunophenotypes, fusion gene transcripts, and clonal immunoglobulin (IG)/T-cell receptor $(T C R)$ gene rearrangements, although additional novel targets are also drawing attention [9-11,24,30-33].

\section{Classical MRD Assays}

MFC identifies the aberrant immunophenotypes in ALL cells. RQ-PCR is used to detect fusion transcripts and clonal IG/TCR gene rearrangements using allele-specific oligonucleotide (ASO) primers, particularly the latter. These assays have sensitivities of $10^{-3}$ to $10^{-5}$; their principles, characteristics, advantages, and disadvantages are summarized in Table 1.

\section{1) Multiparameter flow cytometry (MFC)}

Leukemic cells show expression patterns that differ from those of their normal counterparts and are referred to as leukemia-associated immunophenotypes (LAIPs). These include the asynchronous co-expression of early and late antigens, over- or under-expression of normally expressed antigens, and expression of cross-lineage antigens [34-36]. The principle of the MFC MRD assay is ALL cell recognition through patient-specific LAIP markers combined with backbone markers that enable the gating of lymphoid precursors [34-36]. The patient-specific LAIP should be identified at diagnosis (i.e., before commencing any therapy) by comparing the immunophenotypic profile of the ALL cells to reference bone marrow samples using various combinations of monoclonal antibodies.

MFC MRD is applicable for $>90 \%$ of pediatric ALL [9-11,29,30,37]. Its sensitivity is between $10^{-3}$ and $10^{-5}$ (3-6 colors), which is mainly determined by the number of cells acquired, number of antigens used, degree of immunophenotypic deviation of the leukemic blasts, and the proportion of normal counterparts [26,28,36,38-40]. For example, 1,000,000 events should be acquired to achieve a sensitivity of $10^{-4}$ with a coefficient of variation of $10 \%[36,41]$. The quantity of MRD is usually expressed in percentages; the denominator depends on the protocol used and may be total nucleated cells, total white or nonerythroid cells, or mononuclear cells. Therefore, caution should be taken when comparing MFC MRD results from different laboratories [36].

Compared to those of PCR assays (discussed below), 
Table 1. Characteristics of classical minimal residual disease assays used in pediatric acute lymphoblastic leukemia

\begin{tabular}{|c|c|c|c|}
\hline $\begin{array}{l}\text { Assay technique } \\
\text { and targets }\end{array}$ & $\begin{array}{l}\text { Applicability } \\
\text { and sensitivity }\end{array}$ & Advantages & Disadvantages \\
\hline $\begin{array}{l}\text { Multiparameter } \\
\text { flow cytometry } \\
\text { for LAIPs }\end{array}$ & $\begin{array}{l}>90 \% \\
3-4 \text { colors: } \\
10^{-3}-10^{-4} \\
6-8 \text { colors: } \\
10^{-4}-10^{-5}\end{array}$ & $\begin{array}{l}\text { Wide applicability } \\
\text { Low cost } \\
\text { Short turnaround time } \\
\text { Exclusion of apoptotic cells lacking } \\
\text { leukemogenic potential } \\
\text { Analysis at cell population or single cell level }\end{array}$ & $\begin{array}{l}\text { Lower sensitivity than RQ-PCR } \\
\text { Requires fresh samples }(<24 \mathrm{~h} \text { old }) \\
\text { Requires diagnostic sample to identify LAIPs } \\
\text { Immunophenotypic shifts may cause false negatives } \\
\text { Requires high level of expertise to interpret data } \\
\text { Limited standardization }\end{array}$ \\
\hline $\begin{array}{l}\text { Real-time } \\
\text { quantitative } \\
\text { PCR for fusion } \\
\text { transcripts } \\
\text { (mainly on } \\
\text { RNA) }\end{array}$ & $\begin{array}{l}\text { B-ALL: } \\
\text { 25-30\% } \\
\text { T-ALL: } \\
15-25 \% \\
10^{-4}-10^{-5}\end{array}$ & $\begin{array}{l}\text { High sensitivity } \\
\text { Short turnaround time } \\
\text { Stable target throughout treatment } \\
\text { Wide availability of primer sets } \\
\text { Standardization for recurrent fusion transcripts }\end{array}$ & $\begin{array}{l}\text { Limited applicability } \\
\text { RNA instability } \\
\text { Risk of contamination } \\
\text { Requires standard curves } \\
\text { Risk of inaccurate quantitation } \\
\text { False positive results owing to nonspecific } \\
\text { amplification of normal DNA or of cells } \\
\text { without leukemogenic potential }\end{array}$ \\
\hline $\begin{array}{l}\text { Real-time } \\
\text { quantitative } \\
\text { PCR for } \\
\text { IG/TCR gene } \\
\text { rearrangements }\end{array}$ & $\begin{array}{l}90-95 \% \\
10^{-4}-10^{-5}\end{array}$ & $\begin{array}{l}\text { High sensitivity } \\
\text { Wide applicability } \\
\text { Standardized protocol and data interpretation }\end{array}$ & $\begin{array}{l}\text { Long turnaround time } \\
\text { Generation of patient-specific allele specific } \\
\text { oligonucleotide primer sets is cumbersome } \\
\text { Requires prior knowledge of } I G / T C R \text { gene } \\
\text { rearrangements at diagnosis } \\
\text { Clonal evolution can lead to false negatives } \\
\text { Relative clone load quantitation is affected by } \\
\text { the proportion of } \mathrm{B} / \mathrm{T} \text { lymphoid cells }\end{array}$ \\
\hline
\end{tabular}

B-ALL, B-cell acute lymphoblastic leukemia; IG/TCR, immunoglobulin/T-cell receptor; LAIP, leukemia-associated immunophenotype; MRD, minimal residual disease; RQ-PCR, real-time quantitative polymerase chain reaction; T-ALL, T-cell acute lymphoblastic leukemia.

the main advantages of MFC include its shorter turnaround time (TAT; approximately 4 hours), lower cost, and wider applicability. Hence, this assay is the most widely used for MRD detection in pediatric ALL [9-11, $13,30,31,36,37]$. It excludes apoptotic cells that could contribute to false positive results in PCR assays by gating out cells with high side scatter [37]. Moreover, MFC analyzes antigen expression at the single-cell level but provides data on all cells in the entire sample simultaneously [9-11,30]. Specific immunophenotypes are indicative of the prognosis and/or particular cytogenetic and molecular genetic abnormalities [32,42].

Nevertheless, the sensitivity of MFC is still lower compared to that of PCR assays, and its requirement of fresh samples $(<24 \mathrm{~h}$ old $)$ precludes its use with archived specimens [36,43]. Diagnostic samples are required to identify LAIPs, whereas phenotypic shifts are frequent after treatment or elevated on relapse, which can cause false negative interpretations [35,36]. It requires expert knowledge of antigen expression observed during differentiation of normal hematopoietic progenitors, although the assessment could still be subjective [28,36].

A standardized MRD protocol for B-ALL is available [44]. Standardized antibody panels for 8-color flow cytometry were optimized and validated for the diagnosis and subclassification of hematologic malignancies including ALL; these could be used in the MFC MRD assay as well $[31,34,37,45]$.

\section{2) RQ-PCR for leukemia-specific fusion transcripts}

Leukemia-specific fusion transcripts derived from oncogenic chromosomal rearrangements can be used as MRD targets in pediatric ALL [7,46,47]. ETV6-RUNX1, TCF3-PBX1, and BCR-ABL1 are observed in 25-30\%, 6\%, and $2-4 \%$ of pediatric B-ALLs, respectively $[1,14,16,46-$ 48]. SIL-TAL1 is observed in $15-25 \%$ of pediatric T-ALLs [1,8,46,47,49]. KMT2A gene rearrangement with various partner genes is observed in $80 \%$ of infant B-ALLs $[1,15]$. 
The presence of these fusion transcripts also determines the prognosis of patients with pediatric ALL [14,50]. For MRD assessment, the messenger RNA (mRNA) of the fusion transcript is converted to complementary DNA via reverse-transcription, which is then used as a template for subsequent PCR reactions [46,47,51,52]. During RQ-PCR, the signal from the amplified product is compared to that of a standard curve derived from serial dilutions of a known material, allowing quantification of the PCR product $[14,16,31,47,51,52]$.

The sensitivity of RQ-PCR is comparable to or $1 \mathrm{log}$ higher than that of MFC $\left(10^{-4}-10^{-5}\right)[14,16,49]$. The assay's TAT is comparable to that of MFC [9-11,13,14,16, 30,47,49]. When compared to MFC or to the RQ-PCR assay in terms of detecting clonal IG/TCR gene rearrangements (which target patient-specific LAIPs or index sequences that are affected by immunophenotypic shifts or subclonal evolution during therapy, respectively), this assay targets leukemia-specific fusion transcripts that are theoretically present in all leukemic cells and remain stable throughout treatment $[15,48,50,53]$. Therefore, the same primer set can be used for all patients with the same type of fusion transcripts [46,47,51,52]. Indeed, commercialized primer sets are available for major fusion transcripts, which allows for the widespread adoption of this assay.

Nevertheless, the major drawback of RQ-PCR for fusion transcripts is that it is applicable only to patients with particular fusion transcripts. Other disadvantages include the instability of the RNA and the discordance between the number of cells and number of fusion transcript copies, which depends on the cell cycle $[14,16$, 46-49]. Genomic DNA of rearranged genes can be used instead of mRNA as a starting material owing to its greater stability, easier quantitation (only 1 PCR target is present per cell), and greater availability of information on oligoclonality or clonal evolution [15,16,48,50,51]. However, this is technically cumbersome owing to the high variability of some rearrangement breakpoints between patients thus is not widely used in clinical laboratories [10]. The risk of contamination during the PCR process cannot be avoided regardless of the choice of the starting material.

Standardized RQ-PCR protocols for some recurrent fusion transcripts are available $[31,46,47,51,52]$.

\section{3) RQ-ASO-PCR for clonal IG/TCR gene rearrangements}

The $I G$ and TCR gene loci contain many different variable (V), diversity (D), and joining (J) gene segments [5456]. Serial rearrangement processes known as V(D)J recombinations, which are physiological events essential for immunological diversity, occur during early lymphoid differentiation [54-56]. The combinatorial V(D)J repertoire is estimated to be $\sim 2 \times 10^{6}$ for $I G$ molecules, $\sim 3 \times$ $10^{6}$ for $T C R \alpha \beta$, and $\sim 5 \times 10^{3}$ for $T C R \gamma \delta$ [54]. The random deletion and insertion of nucleotides at the junction sites of each gene segment further diversifies the repertoire during the rearrangement process. The total repertoire of $I G$ and TCR molecules is estimated to reach nearly $10^{12}$ [54]; therefore, it is highly unlikely that two independent B- or T-cell clones carry identical IG/TCR gene rearrangements by chance [54-56]. However, clonal lymphoid cells originating from a single specific lymphoid progenitor have the same (monoclonal) IG/TCR rearrangement, which can therefore serve as a DNA fingerprint [54-56]. Clonal IG/TCR gene rearrangements can be used both for MRD evaluation in lymphoid malignancies and the determination of clonality in conditions with lymphoid proliferation [54,57,58]. Clonal IG/TCR rearrangements are identified using multiplex PCR with different primer sets for IG/TCR genes coupled with heteroduplex analysis or GeneScanning [54]. Junctional regions of clonal $I G / T C R$ rearrangements (the multiplex PCR product) are identified through Sanger sequencing, following which patient-specific complementary ASO primers are designed and RQ-PCR is performed for MRD quantitation [57].

The applicability of RQ-ASO-PCR is comparable to that of MFC (>90\% of pediatric ALL patients) depending on the primer sets used $[8,57,59]$. A sensitivity of $10^{-4}-10^{-5}$ is achieved through the RQ-PCR process $[8,40,59,60]$. It detects patient-specific clones and identifies clonal relationships between two lymphoid malignancies in a single patient and can therefore even differentiate between a 
relapse and second malignancy $[47,54,57,58]$.

Nevertheless, this assay is not widely used in routine clinical practice since the TAT reaches $4-5$ weeks given the ASO-PCR setup for individual patients, even though it has been considered the gold standard for MRD detection in pediatric ALL and is extensively used in MRD research studies along with $\mathrm{MFC}[37,40,59,60]$. Moreover, false positive/negative clonal IG/TCR rearrangement results can arise from either variable performance or misannealing of primers during multiplex PCR as well as the low sensitivity of heteroduplex analysis/GeneScanning (5\% at maximum) at the initial identification of the clonotype [8,22]. Furthermore, RQ-PCR cannot precisely quantify the MRD in cases with very low disease burden, leading to a "positive-not-quantifiable" (PNQ) designation [11]. Non-specific amplification of spurious IG/TCR rearrangements that are indistinguishable from PNQ can also occur, with an intrinsic risk of false positive/negative MRD detection, particularly after the end of therapy or after hematopoietic stem cell transplantation [6,25,27, 31,61,62].

In practice, the combined application of $I G H / I G K$ and TCRB/TCRG gene rearrangements enable MRD marker identification in virtually all pediatric B-ALLs and T-ALLs, respectively $[8,54,56,58]$. Cross-lineage rearrangements are frequently observed in ALL cells (but not in normal counterparts and rarely in mature lymphoid neoplasms); these include TCR gene rearrangements in 40-90\% of B-ALLs and in $20 \%$ of acute myeloid leukemias, as well as $I G$ gene rearrangements in $20 \%$ of T-ALLs $[8,63]$. This implies that cross-lineage rearrangement of $I G$ and TCR genes can be used as a marker for MRD evaluation alone or combined with lineage-restricted rearrangement of $I G$ and TCR genes [8]. However, they should not be used as markers that determine lineage.

Even though this assay is not affected by any treatment-caused immunophenotypic shifts, approximately $20 \%$ of minors with ALL lose their original IG/TCR targets owing to primary and secondary rearrangements resulting from clonal evolution between diagnosis and relapse, risking false negative results during follow-up [33]. Oligoclonality is common in pediatric ALL with different clones of varying therapeutic resistance, which can also lead to false negative results $[59,61]$. Hence, it is recommended that patients with two or more independent $I G / T C R$ gene rearrangement targets be monitored during follow-up [33,40,57,59-61].

A standardized protocol for the detection of clonal IG/TCR gene rearrangements was developed, followed by a guideline for the interpretation and reporting of such data [54,58]. Standardized RQ-PCR guidelines for the analysis of MRD are available to ensure reproducible MRD data across different laboratories [31,57,64].

\section{Emerging MRD Assays}

Emerging MRD assays aim to achieve higher sensitivities and specificities while overcoming the limitations of classical assays. NGF identifies aberrant phenotypes through a standardized high-throughput process; NGS recognizes clonal IG/TCR gene rearrangements, and ddPCR identifies the same as well as fusion transcripts in pediatric ALL; these assays have sensitivities of $10^{-5}$ to $10^{-6}$. The principles, characteristics, advantages, and disadvantages of the emerging MRD assays are summarized in Table 2.

\section{1) Next-generation flow cytometry (NGF)}

NGF is a novel high-throughput MRD assay using flow cytometry that was introduced by the EuroFlow Consortium and is based on a multidimensional approach that includes principal component and canonical analyses [31,32,65-68]. The NGF MRD assay differs from classical MFC MRD testing mainly in that its protocol is fully standardized and that it analyzes $>4$ million cells to achieve a sensitivity of $10^{-5}-10^{-6}[32,41]$. It retains the advantages of MFC including its wide applicability and short TAT [31,32].

Rather than using the LAIP of an individual patient as is performed in the classical MFC MRD assay, the NGF MRD assay recognizes ALL cells using standardized, preset LAIPs that are "different from normal" [32]. This is achieved through comparing the expression of antigenic patterns of ALL cells in numerous patients to that of nor- 
Table 2. Characteristics of emerging minimal residual disease assays used in pediatric acute lymphoblastic leukemia

\begin{tabular}{|c|c|c|c|}
\hline $\begin{array}{c}\text { Assay techniques } \\
\text { and targets }\end{array}$ & $\begin{array}{l}\text { Applicability and } \\
\text { sensitivity }\end{array}$ & Advantages & Disadvantages \\
\hline $\begin{array}{l}\text { Next-generation } \\
\text { flow cytometry } \\
\text { for identifying } \\
\text { immunophenot- } \\
\text { ypic deviations } \\
\text { from normal } \\
\text { counterparts }\end{array}$ & $\begin{array}{l}>90 \% \\
10^{-5}-10^{-6}\end{array}$ & $\begin{array}{l}\text { High sensitivity and wide applicability } \\
\text { Short turnaround time } \\
\text { Does not require prior information on patient-specific } \\
\text { aberrant immunophenotype at diagnosis } \\
\text { Lower risk of false negatives caused by immunophenotypic } \\
\text { shift during therapy compared to MFC } \\
\text { Excludes apoptotic cells lacking leukemogenic potential } \\
\text { Analysis at cell population or single cell level } \\
\text { Standardized for B-ALL }\end{array}$ & $\begin{array}{l}\text { Requires fresh samples } \\
(<24 \mathrm{~h}) \\
\text { Requires } 4 \text { million } \\
\text { cells for a sensitivity } \\
\text { of } 10^{-6} \\
\text { Requires high-level } \\
\text { expertise for } \\
\text { interpretation }\end{array}$ \\
\hline $\begin{array}{l}\text { Next-generation } \\
\text { sequencing for } \\
\text { IG/TCR gene } \\
\text { rearrangements }\end{array}$ & $\begin{array}{l}>90 \% \\
10^{-5}-10^{-6}\end{array}$ & $\begin{array}{l}\text { High sensitivity and wide applicability } \\
\text { Forgoes the need to design patient-specific/allele specific } \\
\text { oligonucleotide primer sets } \\
\text { Does not require knowledge of IG/TCR gene } \\
\text { rearrangement status at the diagnosis } \\
\text { Can identify oligoclonality and clonal evolution } \\
\text { Provides information on B/T-cell background repertoire } \\
\text { Includes internal quality controls to monitor primer } \\
\text { performance, technical variability, and quantitation } \\
\text { Freely available web-based bioinformatics pipeline } \\
\text { Standardized for B-ALL } \\
\text { Potentially useful for other gene mutations }\end{array}$ & $\begin{array}{l}\text { Long turnaround time } \\
\text { Risk of disproportional } \\
\text { target amplification } \\
\text { during multiplex PCR } \\
\text { High cost }\end{array}$ \\
\hline $\begin{array}{l}\text { Digital droplet } \\
\text { PCR for fusion } \\
\text { transcripts or } \\
I G / T C R \text { gene } \\
\text { rearrangements }\end{array}$ & $\begin{array}{l}\text { Applicability varies } \\
\text { depending on targets: } \\
>90 \% \text { for } I G / T C R \\
\text { gene rearrangements } \\
\text { and } 25-30 \% \text { for } \\
\text { fusion transcripts } \\
10^{-5}-10^{-6}\end{array}$ & $\begin{array}{l}\text { High sensitivity and accuracy } \\
\text { Does not require a standard curve } \\
\text { Potentially useful for other gene mutations }\end{array}$ & $\begin{array}{l}\text { Limited experience for } \\
\text { pediatric ALL } \\
\text { Not yet standardized }\end{array}$ \\
\hline
\end{tabular}

B-ALL, B-cell acute lymphoblastic leukemia; IG/TCR, immunoglobulin/T-cell receptor; MFC, multiparameterflow cytometry; PCR, polymerase chain reaction.

mal counterpart populations (hematopoietic progenitors of similar lineage and maturational stage) [28,32,38,39]. It does not require information on the immunophenotype of leukemic cells from each patient at the initial diagnosis and is less affected by immunophenotypic shifts caused by treatment or relapse. The standardized 8-color B-ALL panel includes CD38, CD66c/CD123, CD73/CD304, and CD81 owing to their strong ability to discriminate between B-ALL cells and normal B-cell precursors/regenerating $\mathrm{B}$-cells along with the 5 backbone markers CD19, CD45, CD34, CD10, and CD20 for appropriate Bcell precursor gating as well as differentiation between normal B-cell precursors and B-ALL cells [32,37,69-72]. A fully standardized laboratory protocol that includes equipment settings was established [32]. Upon validation, this assay successfully distinguished patients with B-ALL from normal individuals in $99 \%$ of the subjects [32].

Using the erythrocyte bulky lysis protocol, the NGF MRD assay counts $>4$ million cells las is required for a minimum of 10 clustered events to consider a sample MRD-positive (lower limit of detection) as well as a minimum of 40 clustered events for the accurate quantitation of the MRD level (lower limit of quantitation)], thereby exceeding the sensitivity of RQ-PCR while being comparable to that of NGS [32,73]. This new protocol that involves the resuspension of large amounts of lysed samples was found to increase the number of evaluable leukocytes without significantly altering the cellular composition or increasing the percentage of doublets [32]. By doing so, a concordance of $93 \%$ was achieved between 
the NGF and RQ-PCR assays; most discordances were resolved through NGS for IG/TCR rearrangements and blind multicenter reanalysis of flow cytometric data.

A standardized NGF MRD assay for T-ALLs is expected to be developed based on the current knowledge of the immunophenotypes of neoplastic T-ALL cells and their normal T-cell counterparts $[10,11,34,65]$. The high sensitivity of this assay remains be demonstrated in large clinical trials.

\section{2) Next-generation sequencing (NGS)}

NGS for IG/TCR gene rearrangements is the most intensively studied emerging assay for MRD detection in pediatric ALL [12,21-25]. An amplicon-based multiplex PCR with universal primers for IG/TCR genes followed by deep sequencing provides both the quantity and sequence information of clonal IG/TCR gene rearrangements originating from ALL clones [74]. It is applicable to $>90 \%$ of pediatric ALL (depending on the primer sets used) and shows a high sensitivity (up to $10^{-6}$ ) [21-24, $74]$.

Like the aforementioned RQ-ASO-PCR method, NGS MRD assays can detect clonal IG/TCR gene rearrangements. However, the latter technique has superior specificity for leukemic clones given that it provides sequence details that enable better identification of MRD clones in the presence of background polyclonal rearrangements and allows for better differentiation between relapses of existing clones and second malignancies [21,22,74-76]. The NGS MRD assay sequences multiple IG/TCR rearrangements within a single sequencing run, thus capturing oligoclonality and/or clonal evolution (which is observed in 20\% of relapsed ALLs) during the therapy $[22,58,77]$ and providing an overview of the entire immune repertoire as well as the residual leukemia [25,74-76]. Technique-wise, it requires neither laborious designing of patient-specific RQ-ASO-PCR assays nor a second step for quantitation [74]. It identifies clones of interest in the same sample and does not always require a diagnostic specimen to obtain the index sequence [74-76]. Nevertheless, the assay's high cost and long TAT should be addressed before promoting its rou- tine use in clinical laboratories $[9,10,30]$.

A standardized NGS MRD assay protocol to detect clonal IG/TCR rearrangements in patients with ALL was recently developed and validated [74]. The protocol included a laboratory standard operating procedure for all relevant $I G / T C R$ targets and quality control processes, as well as a web browser-based bioinformatics protocol [74]. Using primers for the genes IGH, IGK, TRB, TRG, and TRD, this assay demonstrated high reproducibility and good concordance with Sanger sequencing [74]. This standardized protocol introduced quality control procedures using two types of materials to monitor the performance of each primer set and better quantify the clonotype $[74,75,78]$. This effort reduces the risk of false positive/negative results due to multiplexing and errors in 'relative' quantitation owing to fluctuating proportions of total $\mathrm{B} / \mathrm{T}$ lymphoid cells to some extent.

As different primers function under the same reaction conditions, NGS is subjected to some variability in the course of library preparation, sequencing, and bioinformatics steps [74]. The 'central poly-target quality control' (cPT-QC) is a standardized mixture of different lymphoid samples representing a full repertoire of $I G / T C R$ gene rearrangements. By checking $c \mathrm{PT}-\mathrm{QC}$ primer usage and comparing assay results with reference profiles, the performance of different primers can be evaluated [74, 75].

The target cells of this assay are lymphocytes, not total leukocytes. Primers for IG/TCR genes amplify only cells with $I G / T C R$ rearrangements in the sample, rendering the percentage of the reads of a particular sequence indicative of the proportion of residual ALL cells among all cells with $I G / T C R$ rearrangements (B/T lymphocytes) and not the proportion of residual ALL cells among the total leukocyte population [75]. This can be problematic when there are too few B- or T- cells (particularly immediately after treatment or B/T-cell-directed immunotherapy) and can lead to the overestimation of the leukemic cell burden [75]. The 'central in-tube quality/quantification control' (cIT-QC) consists of human B- and T-cell lines with known concentrations of both cell types and welldefined $I G / T C R$ rearrangements, and is spiked into each 
sample to undergo concurrent library preparation and sequencing $[74,75]$. As it is subjected to the same technical downstream variables with each sample, it can be used as a library-specific quality control. Simultaneously, the cIT-QC provides a 'read-to-cell count' conversion factor that enables the estimation of the number of cells (specifically, the cell equivalent) with a particular IG/TCR gene rearrangement while not being affected by the number of total B- or T-cells in the sample. Still, caution should be taken when comparing NGS MRD results with those from flow cytometry-based MRD assays, which usually present the quantity of MRD as a percentage of the number of total nucleated cells or total leukocytes [36].

The correlation between the NGS MRD assay for IG/TCR rearrangements and other MRD assays, as well as the clinical usefulness of the high sensitivity of this assay in pediatric ALL, are currently being investigated, and should be examined in larger clinical studies [12,21-25].

\section{3) Droplet digital PCR (ddPCR)}

ddPCR is a highly sensitive third-generation PCR technology that enables absolute quantification [79]. A DNA-containing sample is compartmentalized into oil droplets, and the fluorescence from each droplet is measured at the endpoint after multiple PCR reactions. The fraction of positive droplets (i.e., droplets containing the target DNA) is fitted to a Poisson algorithm, and the absolute copy number is then derived as copies per $1 \mu \mathrm{L}$ without the need for a standard curve. The sample partitioning, high ratio of target DNA molecules to PCR reagents, and endpoint measurements contribute to the high sensitivity $\left(10^{-5}-10^{-6}\right)$ and accuracy of this assay $[79,80]$. This method is also able to quantify samples classified as PNQ according to RQ-PCR [24,80].

Additionally, ddPCR MRD assays measuring the aforementioned leukemia-specific fusion transcripts or IG/TCR gene rearrangements are being explored in different hematologic malignancies including adult ALL [80-84], and is expected to be broadly applied in pediatric ALL in the near future. A standardized protocol for this assay is being developed; prospective clinical trials would de- termine if this assay has additional benefits for pediatric ALL management.

\section{Clinical Significance of MRD and Inter-Assay Correlations}

It was in pediatric ALL that the prognostic significance of MRD quantification was demonstrated for the first time [6]. The prognostic significance of MRD has been extensively investigated in various pediatric ALL settings using classical MRD assays. MRD was strongly associated with early remission, $C R$, relapse after the first $C R$ or allogeneic stem cell transplantation (allo-SCT), event-free survival, and overall survival [6-8,14-18]. Refining risk groups according to MRD level improved patients' outcomes by providing better guidance in terms of treatment reduction or intensification, including whether to pursue allo-SCT [4-6,15,19]. Currently, MRD detection is a component of standard pediatric ALL clinical practice; thresholds of $1 \%, 0.1 \%$, and $0.01 \%$ are used for risk stratification and MRD response assessment [20,31,37,59,85].

In terms of compatibility between the classical MRD assays, MFC and RQ-PCR for IG/TCR gene rearrangements (which are more widely applicable than RQ-PCR for fusion transcripts) have good concordance (>80\%) [29,37,40,59,85-88]. However, it was also reported that that MRD levels differed more than 5-fold between the 2 assays in a substantial proportion of cases [59], as RQ-PCR was more sensitive than MFC even when the sensitivity of the latter was improved by adding colors [40]. Notably, the units of MRD (percentage or cells per volume) as well as the denominators used to calculate MRD percentages (total nucleated cells, total leukocytes, mononuclear cells or lymphoid cells with $I G$ and/or TCR gene rearrangements) differ between assays, as described above. Discrepancies were more frequent in cases with low levels of MRD than in those with high levels of MRD [15,29,37,40,59,85-88]. MFC-negative/RQ-PCR-positive cases could be a consequence of the limited sensitivity of flow cytometry analysis in the $<10^{-4}$ range, immunophenotypic changes during therapy (false negative MFC), or non-specific amplification of normal DNA or dam- 
aged residual ALL cells without leukemogenic potential (false positive RQ-PCR) [27,35,36,40,59]. The denominator effects in RQ-PCR (particularly for IG/TCR gene rearrangements) may also contribute to discrepancies [59]. MFC-positive/RQ-PCR-negative cases can be attributed to additional IG/TCR gene rearrangements occurring during clonal evolution or the outgrowth of a subclone that is not targeted as an index clone [59]. It has been suggested that pediatric patients with B-ALL who have discordant results experience intermediate clinical outcomes compared to those with concordant positive or negative results [85]. It remains controversial whether the concordance depends on the time of sampling $[85,86]$.

The quantitative correlation between RQ-PCR for fusion transcript versus that for IG/TCR gene rearrangements has been investigated less frequently $[15,16,77]$. RQ-PCR for ETV6-RUNX1 (RNA-based) and that for TCR gene rearrangements showed good agreement, with the former being slightly more sensitive when good quality RNA was available [16]. This could have been because the RNA transcript is not always proportional to the number of leukemic cells but may vary depending on the cell cycle, as mentioned above [16]. A study of infant ALL that examined $K M T 2 A$ gene rearrangements using DNAbased RQ-PCR showed a concordance of 65\% (i.e., less than a threefold difference) with RQ-PCR for IG/TCR gene rearrangements [15]. In $10 \%$ of their samples, the MRD load observed in the KMT2A gene assay was higher than that of the IG/TCR gene counterpart, probably because $K M T 2 A$ rearrangements are assumed to be present in the total leukemic clone. This contrasts with the frequent oligoclonal IG/TCR rearrangements in infants, demonstrating the usefulness of RQ-PCR for detecting fusion transcripts in MRD diagnostics. Comparisons between MFC and RQ-PCR for fusion transcripts have rarely been performed.

Overall, most studies concluded that all the classical assays are efficient tools for monitoring MRD in pediatric ALL [37,86-88] and recommended the combined use of different MRD assays to prevent false positive/negative results and to better refine risk stratification $[15,29,85$, 86].
To date, the clinical significance of emerging MRD assays, as well as their inter-assay correlations and concordance with classical MRD assays, have been investigated in only a few pediatric ALL studies [12,21-25]. NGF versus NGS MRD assays for IGH gene rearrangements correlated to a certain extent in a previous study, although NGS was superior in detecting MRD [21]. This study showed that the NGS assay has excellent analytical performance, including high sensitivity (0.0001\%). In studies that compared the NGS MRD assay for IG/TCR gene rearrangements to MFC or RQ-PCR assays for the same MRD targets [12,22,23], NGS correlated well with RQ-PCR in terms of target identification [22], and NGS MRD assays predicted relapse and survival in minors with ALL more accurately than did MFC $[12,23]$. The ddPCR MRD assay was as sensitive as RQ-PCR and provided potentially more accurate prognostic stratification for cases defined as PNQ MRD via RQ-PCR through more precise quantification [24]. NGS and ddPCR MRD assay data from adults with ALL or mature lymphoid malignancies were well-correlated with each other and with those of classical MRD assays; this was consistent with good analytical performance and accurate prognostic stratification [80, 84]. Upcoming large clinical trials could help incorporate such emerging MRD assays into international practice guideline for pediatric ALL.

\section{Other Considerations}

\section{1) Samples}

MRD is comparable in the peripheral blood (PB) and bone marrow (BM) of patients with T-ALL; however, those with B-ALL have 1-3 logs lower MRD in PB than in BM. Therefore, BM is the preferred tissue for MRD testing in B-ALL and is also used in T-ALL testing $[10,11$, 89-91]. The possibility of using PB is still being investigated for both classical and emerging MRD assays given its convenience, but supporting evidence is insufficient to date [86,89-91].

Because MRD testing is quantitative, the representativeness of the sample is critical. BM aspirates submitted for MRD analysis invariably contain some PB [36,92]. The 
evaluation of $\mathrm{PB}$ contamination has been proposed using flow cytometry to detect CD117+ mast cells, B-cell precursors and nucleated red cells [73], the intensity of CD16 on maturing neutrophils [36], as well as plasma cells, CD34+ cells, and CD10+ granulocytes [92]. However, these techniques are not widely used, and practical methods should be developed and standardized to better evaluate the representativeness of samples for MRD assays.

\section{2) MRD assays designed to detect new targets}

The discovery and evaluation of new targets would contribute to improving MRD monitoring in pediatric ALL. IKZF1 deletion is a secondary alteration associated with unfavorable outcomes in pediatric B-ALL, and is observed mainly in BCR-ABL1-positive B-ALL $(\sim 65 \%)$ as well as in BCR-ABL1-like B-ALL $(\sim 35 \%)$ [48,93]. The $I K Z F 1$ deletion was previously shown to be closely correlated with $I G / T C R$ MRD markers, suggesting its own potential as an MRD marker [94].

Early T-cell precursor ALL is a high-risk T-ALL characterized by absent (i.e., not yet occurred owing to its immaturity) or oligoclonal $I G / T C R$ gene rearrangement, as well as the coexpression of myeloid antigens [95]. FLT3-internal tandem duplication is frequently observed and can be used as a molecular marker in this disease as it is in acute myeloid leukemia [96].

\section{3) Flow cytometry-based MRD evaluation in patients undergoing immunotherapy}

Immunotherapeutic strategies have moved to the forefront of ALL treatments aimed at reducing MRD levels and/or decreasing conventional chemotherapy-related toxicities [97]. The three representative approaches are the (i) CD3/CD19 bispecific T-cell binder blinatumomab, (ii) CD22-directed antibody drug conjugate inotuzumab ozogamicin, and (iii) CD19-directed chimeric antigen receptor T-cell (the so-called CAR-T therapy) [97]. MRD evaluation can assess the efficacy of these novel treatments and serve as a surrogate marker for the endpoint [30]. However, flow cytometry-based MRD assays could be problematic particularly in B-ALL patients receiving immunotherapy since, in principle, these therapies tar- get particular B-cell markers (CD19 and CD22) to identify B-ALL cells, which are also the markers used to gate B-cell precursors in flow cytometry [32]. Alternative strategies for detecting residual CD19-negative B-ALL cells using other B-cell markers such as CD22 or CD24 could be employed [98]. Overall, a standardized protocol for MRD evaluation in pediatric patients with B-ALL who are receiving immunotherapy remains to be developed.

\section{Conclusion}

MRD has been proven to be the strongest prognostic factor in pediatric ALL. MRD evaluation expedites personalized medicine in pediatric ALL by enabling accurate risk group assignment and risk-adapted treatment. For routine use, MRD assays should have clinically relevant sensitivity and specificity, reproducibility, applicability, appropriate TAT, and technical feasibility. MFC- or RQ-PCR-based classical MRD assays show sensitivities of $10^{-3}$ to $10^{-5}$ and have mainly been standardized by European working groups. Novel techniques such as NGF, NGS, and ddPCR are promising alternatives given their improved sensitivities $\left(10^{-5}\right.$ to $\left.10^{-6}\right)$, specificity for ALL clones, applicability, and technical feasibility compared to classical MRD assays. These methods aim to overcome the drawbacks of classical assays and improved prognostic stratification. Prospective clinical trials ought to clarify the clinical benefit of the high sensitivities of these emerging assays in pediatric ALL. Standardization efforts and quality assurance programs are expected to be pursued through international collaborations to allow for the actual implementation of the emerging assays in clinical laboratories. In the meantime, efforts to unveil new targets and improve existing methods continue.

\section{Conflict of Interest Statement}

The authors have no conflict of interest to declare.

\section{References}

1. Swerdlow SH, Campo E, Harris NL, et al, eds. WHO classi- 
fication of tumours of haematopoietic and lymphoid tissues. Revised 4th ed. Lyon: IARC Press, 2017.

2. Park HJ, Moon EK, Yoon JY, et al. Incidence and survival of childhood cancer in Korea. Cancer Res Treat 2016;48:86982.

3. Siegel DA, Henley SJ, Li J, Pollack LA, Van Dyne EA, White A. Rates and trends of pediatric acute lymphoblastic leukemia - United States, 2001-2014.

4. Vora A, Goulden N, Wade R, et al. Treatment reduction for children and young adults with low-risk acute lymphoblastic leukaemia defined by minimal residual disease (UKALL 2003): a randomised controlled trial. Lancet Oncol 2013;14:199-209.

5. Pieters R, de Groot-Kruseman H, Van der Velden V, et al. Successful therapy reduction and intensification for childhood acute lymphoblastic leukemia based on minimal residual disease monitoring: study ALL10 from the Dutch Childhood Oncology Group. J Clin Oncol 2016;34:2591-601.

6. van Dongen JJ, Seriu T, Panzer-Grümayer ER, et al. Prognostic value of minimal residual disease in acute lymphoblastic leukaemia in childhood. Lancet 1998;352:1731-8.

7. Cavé H, van der Werff ten Bosch J, Suciu S, et al. Clinical significance of minimal residual disease in childhood acute lymphoblastic leukemia. European Organization for Research and Treatment of Cancer--Childhood Leukemia Cooperative Group. N Engl J Med 1998;339:591-8.

8. Flohr T, Schrauder A, Cazzaniga G, et al. Minimal residual disease-directed risk stratification using real-time quantitative PCR analysis of immunoglobulin and T-cell receptor gene rearrangements in the international multicenter trial AIEOP-BFM ALL 2000 for childhood acute lymphoblastic leukemia. Leukemia 2008;22:771-82.

9. Chen X, Wood BL. Monitoring minimal residual disease in acute leukemia: technical challenges and interpretive complexities. Blood Rev 2017:31:63-75.

10. Della Starza I, Chiaretti S, De Propris MS, et al. Minimal residual disease in acute lymphoblastic leukemia: technical and clinical advances. Front Oncol 2019;9:726.

11. Kim IS. Minimal residual disease in acute lymphoblastic leukemia: technical aspects and implications for clinical interpretation. Blood Res 2020;55:S19-26.

12. Wood B, Wu D, Crossley B, et al. Measurable residual disease detection by high-throughput sequencing improves risk stratification for pediatric B-ALL. Blood 2018;131:1350-9.

13. Short NJ, Jabbour E. Minimal residual disease in acute lymphoblastic leukemia: how to recognize and treat it. Curr Oncol Rep 2017:19:6.

14. Cazzaniga G, Lanciotti M, Rossi V, et al. Prospective molecular monitoring of BCR/ABL transcript in children with $\mathrm{Ph}+$ acute lymphoblastic leukaemia unravels differences in treatment response. Br J Haematol 2002;119:445-53.

15. Van der Velden VH, Corral L, Valsecchi MG, et al. Prognostic significance of minimal residual disease in infants with acute lymphoblastic leukemia treated within the Interfant-99 protocol. Leukemia 2009;23:1073-9.

16. Drunat S, Olivi M, Brunie G, et al. Quantification of TELAML1 transcript for minimal residual disease assessment in childhood acute lymphoblastic leukaemia. Br J Haematol
2001;114:281-9.

17. Bader P, Kreyenberg H, Henze GH, et al. Prognostic value of minimal residual disease quantification before allogeneic stem-cell transplantation in relapsed childhood acute lymphoblastic leukemia: the ALL-REZ BFM Study Group. J Clin Oncol 2009;27:377-84.

18. Berry DA, Zhou S, Higley H, et al. Association of minimal residual disease with clinical outcome in pediatric and adult acute lymphoblastic leukemia: a meta-analysis. JAMA Oncol 2017;3:e170580.

19. Eckert C, Henze G, Seeger K, et al. Use of allogeneic hematopoietic stem-cell transplantation based on minimal residual disease response improves outcomes for children with relapsed acute lymphoblastic leukemia in the intermediaterisk group. J Clin Oncol 2013;31:2736-42.

20. National Comprehensive Cancer Network. Pediatric acute lymphoblastic leukemia (Version 2.2020). Plymouth Meeting, PA: National Comprehensive Cancer Network, 2020. (Accessed June 3, 2020, at https://www.nccn.org/professionals/physician_ gls/pdf/ped_all.pdf)

21. Cheng S, Inghirami G, Cheng S, Tam W. Simple deep sequencing-based post-remission MRD surveillance predicts clinical relapse in B-ALL. J Hematol Oncol 2018;11:105.

22. Theunissen PMJ, de Bie M, van Zessen D, de Haas V, Stubbs AP, van der Velden VHJ. Next-generation antigen receptor sequencing of paired diagnosis and relapse samples of B-cell acute lymphoblastic leukemia: clonal evolution and implications for minimal residual disease target selection. Leuk Res 2019;76:98-104

23. Pulsipher MA, Carlson C, Langholz B, et al. IgH-V(D)J NGSMRD measurement pre- and early post-allotransplant defines very low- and very high-risk ALL patients. Blood 2015;125: 3501-8.

24. Della Starza I, Nunes V, Lovisa F, et al. Digital-droplet PCR, an accurate method for IG/TR PCR-MRD stratification in childhood acute lymphoblastic leukemia. Blood 2018:132: 1544.

25. Kotrova M, Muzikova K, Mejstrikova E, et al. The predictive strength of next-generation sequencing MRD detection for relapse compared with current methods in childhood ALL. Blood 2015;126:1045-7.

26. Theunissen PMJ, Sedek L, De Haas V, et al. Detailed immunophenotyping of $\mathrm{B}$-cell precursors in regenerating bone marrow of acute lymphoblastic leukaemia patients: implications for minimal residual disease detection. $\mathrm{Br} \mathrm{J}$ Haematol 2017;178:257-66.

27. Fronkova E, Muzikova K, Mejstrikova E, et al. B-cell reconstitution after allogeneic SCT impairs minimal residual disease monitoring in children with ALL. Bone Marrow Transplant 2008;42:187-96.

28. Theunissen PMJ, van den Branden A, Van Der Sluijs-Gelling A, et al. Understanding the reconstitution of the B-cell compartment in bone marrow and blood after treatment for B-cell precursor acute lymphoblastic leukaemia. Br J Haematol 2017; 178:267-78.

29. Kerst G, Kreyenberg H, Roth C, et al. Concurrent detection of minimal residual disease (MRD) in childhood acute lym- 
phoblastic leukaemia by flow cytometry and real-time PCR. Br J Haematol 2005;128:774-82.

30. van Dongen JJ, van der Velden VH, Brüggemann M, Orfao A. Minimal residual disease diagnostics in acute lymphoblastic leukemia: need for sensitive, fast, and standardized technologies. Blood 2015;125:3996-4009.

31. Brüggemann M, Schrauder A, Raff T, et al. Standardized MRD quantification in European ALL trials: proceedings of the Second International Symposium on MRD assessment in Kiel, Germany, 18-20 September 2008. Leukemia 2010;24:521-35.

32. Theunissen P, Mejstrikova E, Sedek L, et al. Standardized flow cytometry for highly sensitive MRD measurements in B-cell acute lymphoblastic leukemia. Blood 2017;129:347-57.

33. de Haas V, Verhagen OJ, von dem Borne AE, Kroes W, van den Berg H, van der Schoot CE. Quantification of minimal residual disease in children with oligoclonal B-precursor acute lymphoblastic leukemia indicates that the clones that grow out during relapse already have the slowest rate of reduction during induction therapy. Leukemia 2001;15:134-40.

34. van Dongen JJ, Lhermitte L, Böttcher S, et al. EuroFlow antibody panels for standardized n-dimensional flow cytometric immunophenotyping of normal, reactive and malignant leukocytes. Leukemia 2012;26:1908-75.

35. Chen W, Karandikar NJ, McKenna RW, Kroft SH. Stability of leukemia-associated immunophenotypes in precursor B-lymphoblastic leukemia/lymphoma: a single institution experience. Am J Clin Pathol 2007:127:39-46.

36. Wood BL. Principles of minimal residual disease detection for hematopoietic neoplasms by flow cytometry. Cytometry B Clin Cytom 2016;90:47-53.

37. Irving J, Jesson J, Virgo P, et al. Establishment and validation of a standard protocol for the detection of minimal residual disease in B lineage childhood acute lymphoblastic leukemia by flow cytometry in a multi-center setting. Haematologica 2009;94:870-4.

38. van Lochem EG, van der Velden VH, Wind HK, te Marvelde JG, Westerdaal NA, van Dongen JJ. Immunophenotypic differentiation patterns of normal hematopoiesis in human bone marrow: reference patterns for age-related changes and disease-induced shifts. Cytometry B Clin Cytom 2004;60:113.

39. Orfao A, Matarraz S, Pérez-Andrés M, et al. Immunophenotypic dissection of normal hematopoiesis. J Immunol Methods 2019; 475:112684.

40. Denys B, van der Sluijs-Gelling AJ, Homburg C, et al. Improved flow cytometric detection of minimal residual disease in childhood acute lymphoblastic leukemia. Leukemia 2013; 27:635-41.

41. Arroz M, Came N, Lin P, et al. Consensus guidelines on plasma cell myeloma minimal residual disease analysis and reporting. Cytometry B Clin Cytom 2016;90:31-9.

42. Wang XM. Advances and issues in flow cytometric detection of immunophenotypic changes and genomic rearrangements in acute pediatric leukemia. Transl Pediatr 2014;3:149-55.

43. Diks AM, Bonroy C, Teodosio C, et al. Impact of blood storage and sample handling on quality of high dimensional flow cytometric data in multicenter clinical research. J Immunol
Methods 2019;475:112616.

44. Lucio P, Gaipa G, van Lochem EG, et al. BIOMED-I concerted action report: flow cytometric immunophenotyping of precursor B-ALL with standardized triple-stainings. BIOMED-1 concerted action investigation of minimal residual disease in acute leukemia: international standardization and clinical evaluation. Leukemia 2001;15:1185-92.

45. Kalina T, Flores-Montero J, van der Velden VH, et al. EuroFlow standardization of flow cytometer instrument settings and immunophenotyping protocols. Leukemia 2012;26:1986-2010.

46. van Dongen JJ, Macintyre EA, Gabert JA, et al. Standardized RT-PCR analysis of fusion gene transcripts from chromosome aberrations in acute leukemia for detection of minimal residual disease. Report of the BIOMED-1 Concerted Action: investigation of minimal residual disease in acute leukemia. Leukemia 1999;13:1901-28.

47. Gabert J, Beillard E, van der Velden VH, et al. Standardization and quality control studies of 'real-time' quantitative reverse transcriptase polymerase chain reaction of fusion gene transcripts for residual disease detection in leukemia - a Europe against cancer program. Leukemia 2003;17:2318-57.

48. Cazzaniga G, van Delft FW, Lo Nigro L, et al. Developmental origins and impact of BCR-ABL1 fusion and IKZF1 deletions in monozygotic twins with $\mathrm{Ph}+$ acute lymphoblastic leukemia. Blood 2011;118:5559-64.

49. Chen X, Pan Q, Stow P, et al. Quantification of minimal residual disease in T-lineage acute lymphoblastic leukemia with the TAL-1 deletion using a standardized real-time PCR assay. Leukemia 2001;15:166-70

50. Konrad M, Metzler M, Panzer S, et al. Late relapses evolve from slow-responding subclones in t(12;21)-positive acute lymphoblastic leukemia: evidence for the persistence of a preleukemic clone. Blood 2003;101:3635-40.

51. van der Velden VH, Hochhaus A, Cazzaniga G, Szczepanski T, Gabert J, van Dongen JJ. Detection of minimal residual disease in hematologic malignancies by real-time quantitative PCR: principles, approaches, and laboratory aspects. Leukemia 2003;17:1013-34.

52. Pfeifer H, Cazzaniga G, van der Velden VHJ, et al. Standardisation and consensus guidelines for minimal residual disease assessment in Philadelphia-positive acute lymphoblastic leukemia $(\mathrm{Ph}+\mathrm{ALL})$ by real-time quantitative reverse transcriptase PCR of e1a2 BCR-ABL1. Leukemia 2019;33:1910-22.

53. Ford AM, Fasching K, Panzer-Grümayer ER, Koenig M, Haas OA, Greaves MF. Origins of "late" relapse in childhood acute lymphoblastic leukemia with TEL-AML1 fusion genes. Blood 2001;98:558-64.

54. van Dongen JJ, Langerak AW, Brüggemann M, et al. Design and standardization of PCR primers and protocols for detection of clonal immunoglobulin and T-cell receptor gene recombinations in suspect lymphoproliferations: report of the BIOMED-2 concerted action BMH4-CT98-3936. Leukemia 2003;17:2257-317.

55. Cazzaniga G, Biondi A. Molecular monitoring of childhood acute lymphoblastic leukemia using antigen receptor gene rearrangements and quantitative polymerase chain reaction technology. Haematologica 2005;90:382-90. 
56. Brüggemann $\mathrm{M}$, White $\mathrm{H}$, Gaulard $\mathrm{P}$, et al. Powerful strategy for polymerase chain reaction-based clonality assessment in T-cell malignancies report of the BIOMED-2 concerted action BHM4 CT98-3936. Leukemia 2007:21:215-21.

57. van der Velden VH, Cazzaniga G, Schrauder A, et al. Analysis of minimal residual disease by Ig/TCR gene rearrangements: guidelines for interpretation of real-time quantitative PCR data. Leukemia 2007;21:604-11.

58. Langerak AW, Groenen PJ, Brüggemann M, et al. EuroClonality/ BIOMED-2 guidelines for interpretation and reporting of Ig/TCR clonality testing in suspected lymphoproliferations. Leukemia 2012;26:2159-71.

59. Malec M, van der Velden VH, Björklund E, et al. Analysis of minimal residual disease in childhood acute lymphoblastic leukemia: comparison between RQ-PCR analysis of Ig/TcR gene rearrangements and multicolor flow cytometric immunophenotyping. Leukemia 2004;18:1630-6.

60. van der Velden VH, Noordijk R, Brussee M, et al. Minimal residual disease diagnostics in acute lymphoblastic leukaemia: impact of primer characteristics and size of junctional regions. Br J Haematol 2014;164:451-3.

61. de Haas V, Verhagen OJ, von dem Borne AE, Kroes W, van den Berg H, van der Schoot CE. Quantification of minimal residual disease in children with oligoclonal B-precursor acute lymphoblastic leukemia indicates that the clones that grow out during relapse already have the slowest rate of reduction during induction therapy. Leukemia 2001;15:134-40.

62. van der Velden VH, Wijkhuijs JM, van Dongen JJ. Non-specific amplification of patient-specific Ig/TCR gene rearrangements depends on the time point during therapy: implications for minimal residual disease monitoring. Leukemia 2008;22:641-4.

63. Przybylski G, Oettle H, Ludwig WD, Siegert W, Schmidt CA. Molecular characterization of illegitimate TCR delta gene rearrangements in acute myeloid leukaemia. $\mathrm{Br} \mathrm{J}$ Haematol 1994:87:301-7.

64. van der Velden VH, Panzer-Grümayer ER, Cazzaniga G, et al. Optimization of PCR-based minimal residual disease diagnostics for childhood acute lymphoblastic leukemia in a multi-center setting. Leukemia 2007;21:706-13.

65. Pedreira CE, Costa ES, Lecrevisse Q, van Dongen JJ, Orfao A; EuroFlow Consortium. Overview of clinical flow cytometry data analysis: recent advances and future challenges. Trends Biotechnol 2013;31:415-25.

66. Flores-Montero J, Sanoja-Flores L, Paiva B, et al. Next generation flow for highly sensitive and standardized detection of minimal residual disease in multiple myeloma. Leukemia 2017;31:2094-103.

67. Lhermitte L, Mejstrikova E, van der Sluijs-Gelling AJ, et al. Automated database-guided expert-supervised orientation for immunophenotypic diagnosis and classification of acute leukemia. Leukemia 2018;32:874-81.

68. Costa ES, Pedreira CE, Barrena S, et al. Automated pattern-guided principal component analysis vs expert-based immunophenotypic classification of B-cell chronic lymphoproliferative disorders: a step forward in the standardization of clinical immunophenotyping. Leukemia 2010;24:1927-33.
69. Wang W, Gao L, Li Y, et al. The application of CD73 in minimal residual disease monitoring using flow cytometry in B-cell acute lymphoblastic leukemia. Leuk Lymphoma 2016; 57:1174-81.

70. Solly F, Angelot F, Garand R, et al. CD304 is preferentially expressed on a subset of B-lineage acute lymphoblastic leukemia and represents a novel marker for minimal residual disease detection by flow cytometry. Cytometry A 2012;81: $17-24$.

71. Muzzafar T, Medeiros LJ, Wang SA, Brahmandam A, Thomas DA, Jorgensen JL. Aberrant underexpression of CD81 in precursor B-cell acute lymphoblastic leukemia: utility in detection of minimal residual disease by flow cytometry. Am J Clin Pathol 2009;132:692-8.

72. Djokic M, Björklund E, Blennow E, Mazur J, Söderhäll S, Porwit A. Overexpression of CD123 correlates with the hyperdiploid genotype in acute lymphoblastic leukemia. Haematologica 2009;94:1016-9.

73. Arroz M, Came N, Lin P, et al. Consensus guidelines on plasma cell myeloma minimal residual disease analysis and reporting. Cytometry B Clin Cytom 2016;90:31-9.

74. Brüggemann $M$, Kotrová $M$, Knecht $H$, et al. Standardized next-generation sequencing of immunoglobulin and T-cell receptor gene recombinations for MRD marker identification in acute lymphoblastic leukaemia; a EuroClonality-NGS validation study. Leukemia 2019;33:2241-53.

75. Knecht H, Reigl T, Kotrová M, et al. Quality control and quantification in IG/TR next-generation sequencing marker identification: protocols and bioinformatic functionalities by EuroClonality-NGS. Leukemia 2019;33:2254-65.

76. Scheijen B, Meijers RWJ, Rijntjes J, et al. Next-generation sequencing of immunoglobulin gene rearrangements for clonality assessment: a technical feasibility study by EuroClonalityNGS. Leukemia 2019;33:2227-40.

77. Jo I, Chung NG, Lee $S$, et al. Considerations for monitoring minimal residual disease using immunoglobulin clonality in patients with precursor B-cell lymphoblastic leukemia. Clin Chim Acta 2019;488:81-9.

78. Bystry V, Reigl T, Krejci A, et al. RResT/Interrogate: an interactive immunoprofiler for IG/TR NGS data. Bioinformatics 2017:33:435-7.

79. Huggett JF, Cowen S, Foy CA. Considerations for digital PCR as an accurate molecular diagnostic tool. Clin Chem 2015; 61:79-88

80. Della Starza I, De Novi LA, Santoro A, et al. Digital droplet PCR and next-generation sequencing refine minimal residual disease monitoring in acute lymphoblastic leukemia. Leuk Lymphoma 2019;60:2838-40.

81. Drandi D, Ferrero S, Ladetto M. Droplet digital PCR for minimal residual disease detection in mature lymphoproliferative disorders. Methods Mol Biol 2018;1768:229-56.

82. Brunetti C, Anelli L, Zagaria A, et al. Droplet digital PCR is a reliable tool for monitoring minimal residual disease in acute promyelocytic leukemia. J Mol Diagn 2017;19:437-44.

83. Wang WJ, Zheng CF, Liu Z, et al. Droplet digital PCR for BCR/ABL(P210) detection of chronic myeloid leukemia: A high sensitive method of the minimal residual disease and 
disease progression. Eur J Haematol 2018;101:291-6.

84. Coccaro N, Anelli L, Zagaria A, et al. Droplet digital PCR is a robust tool for monitoring minimal residual disease in adult Philadelphia-positive acute lymphoblastic leukemia. J Mol Diagn 2018;20:474-82.

85. Gaipa G, Cazzaniga G, Valsecchi MG, et al. Time point-dependent concordance of flow cytometry and real-time quantitative polymerase chain reaction for minimal residual disease detection in childhood acute lymphoblastic leukemia. Haematologica 2012;97:1582-93.

86. Neale GA, Coustan-Smith E, Stow P, et al. Comparative analysis of flow cytometry and polymerase chain reaction for the detection of minimal residual disease in childhood acute lymphoblastic leukemia. Leukemia 2004;18:934-8.

87. Thörn I, Forestier E, Botling J, et al. Minimal residual disease assessment in childhood acute lymphoblastic leukaemia: a Swedish multi-centre study comparing real-time polymerase chain reaction and multicolour flow cytometry. Br J Haematol 2011;152:743-53.

88. Stark B, Avigad S, Luria D, et al. Bone marrow minimal disseminated disease (MDD) and minimal residual disease (MRD) in childhood T-cell lymphoblastic lymphoma stage III, detected by flow cytometry (FC) and real-time quantitative polymerase chain reaction (RQ-PCR). Pediatr Blood Cancer 2009;52:20-5.

89. van der Velden VH, Jacobs DC, Wijkhuijs AJ, et al. Minimal residual disease levels in bone marrow and peripheral blood are comparable in children with $\mathrm{T}$ cell acute lymphoblastic leukemia (ALL), but not in precursor-B-ALL. Leukemia 2002; 16:1432-6

90. Coustan-Smith E, Sancho J, Hancock ML, et al. Use of peripheral blood instead of bone marrow to monitor residual disease in children with acute lymphoblastic leukemia. Blood 2002;100:2399-402.

91. Schumich A, Maurer-Granofszky M, Attarbaschi A, et al. Flow-cytometric minimal residual disease monitoring in blood predicts relapse risk in pediatric B-cell precursor acute lymphoblastic leukemia in trial AIEOP-BFM-ALL 2000. Pediatr Blood Cancer 2019;66:e27590.

92. Delgado JA, Guillén-Grima F, Moreno C, et al. A simple flow-cytometry method to evaluate peripheral blood contamination of bone marrow aspirates. J Immunol Methods 2017;442:54-8.

93. Stanulla M, Cavé H, Moorman AV. IKZF1 deletions in pediatric acute lymphoblastic leukemia: still a poor prognostic marker? Blood 2020;135:252-60.

94. Venn NC, van der Velden VH, de Bie M, et al. Highly sensitive MRD tests for ALL based on the IKZF1 $\Delta 3-6$ microdeletion. Leukemia 2012;26:1414-6.

95. Noronha EP, Marques LVC, Andrade FG, et al. The profile of immunophenotype and genotype aberrations in subsets of pediatric T-cell acute lymphoblastic leukemia. Front Oncol 2019;9:316.

96. Levis MJ, Perl AE, Altman JK, et al. A next-generation sequencing-based assay for minimal residual disease assessment in AML patients with FLT3-ITD mutations. Blood Adv 2018;2:825-31.

97. Winters A, Gore L. Moving immunotherapy into the front line in ALL. Hematology Am Soc Hematol Educ Program 2019; 2019:209-17.

98. Cherian S, Miller V, McCullouch V, et al. A novel flow cytometric assay for detection of residual disease in patients with B-lymphoblastic leukemia/lymphoma post anti-CD19 therapy. Cytometry B Clin Cytom 2018;94:112-20. 